\title{
Produção de vídeos na perspectiva da aprendizagem multimídia
}

\author{
Patrício Eduardo Orozco Contreras - PPGTER/ UFSM - orozco.contreras@ gmail.com \\ Ricardo Machado Ellensohn - UNIPAMPA/Caçapava - ricardoellensohn@ gmail.com \\ Claudia Smaniotto Barin - PPGTER/UFSM - claudiabarin@nte.ufsm.br
}

\begin{abstract}
Resumo: O presente trabalho analisa e discute as potencialidades, desafios de produção e características de design do vídeo como fonte de informação e referência para os estudantes do Curso de Música e Tecnologia da UFSM. O trabalho consiste num estudo descritivo qualitativo de cunho crítico-reflexivo acerca de um relato de experiência a partir de uma prática já existente na disciplina complementar de graduação: Áudio Digital Multipista I, II, II e IV, revista, analisada e comparada com o modelo de Clark e Mayer de Instrucional Design. Com base nos resultados obtidos nessa experiência sustentamos a tese de que a produção de vídeos considerando os princípios do Design Instrucional é viável e impacta na qualidade educacional do material produzido uma vez que gerencia a carga cognitiva.
\end{abstract}

Palavras-chave: vídeo educacional. carga cognitiva. design instrucional. aprendizagem multimídia

\section{Video production from the perspective of multimedia learning}

Abstract: The present work analyzes and discusses the potential, production challenges and design characteristics of video as an information source and reference for the students of UFSM's Program of Music and Technology. The work consists of a qualitative descriptive study with critical-reflexive approach about an experience report based on an existing practice in the complementary courses of Digital Multitrack Audio I, II, III and IV, revised, analyzed and compared with the Instructional Design model of Clark and Mayer. Based on the results gathered through this experience, we sustain the thesis that the production of videos considering the Instructional Design Principles is viable and it has positive impact on the educational quality of produced material, since it effectively manages cognitive load.

Keywords: educational video. cognitive load. instructional design. multimedia learning

\section{Introdução}

O Curso de Música e Tecnologia da Universidade Federal de Santa Maria é o primeiro curso superior deste tipo numa universidade pública no Brasil, e sendo assim enfrenta grandes desafios numa área onde o processo de ensino e aprendizagem está em pleno desenvolvimento, e onde novos enfoques e estratégias podem contribuir positivamente (TOULSON, 2011). Sendo uma área de estudo inerentemente interdisciplinar, englobando disciplinas diversas como a matemática, informática, acústica, música e psicologia, estabelece-se o desafio de manter o interesse e a motivação dos estudantes ao mesmo tempo em que o assunto é abordado com profundidade dentro do curso (ibid.).

Outra particularidade do ensino de Música e Tecnologia é que além da abordagem de ensino em sala de aula o compartilhamento de vivências é uma prática comum. Essa prática permite aos estudantes e professores interagirem mais eficientemente, potencializando o processo de aprendizagem, sendo as questões de cunho teórico abordadas de acordo com as necessidades e exigências do contexto (PRENSKY, 2007).

$\mathrm{Na}$ medida em que procuramos adaptar nossa proposta de ensino e aprendizagem ao contexto e à realidade de nossos estudantes e seu universo de vivências, é possível 
aumentar sua motivação individual e ao mesmo tempo potencializar as oportunidades de consolidação do processo de aprendizagem significativa (KARPPINEN, 2005). A expressão e o conceito de aprendizagem significativa se refere inicialmente ao proposto por Ausubel em 1968 quando sugere que para que esta ocorra é necessário que haja ou um mecanismo de aprendizagem significativa ou que se apresente um material potencialmente significativo para o aprendiz (expressão usada pelo autor). Ele estabelece ainda que para que este material possa ser significativo ele deve estar relacionado a idéias e conceitos previamente presentes na estrutura cognitiva do aprendiz com as quais ele possa relacionar este novo conteúdo. Ressalta ainda a individualidade do processo já que cada estrutura cognitiva é inerentemente individual assim como serão os novos significados adquiridos (AUSUBEL, 2000).

Uma proposta de procuramos investigar e aproximar à nossa prática é a de conciliar o potencial para a aprendizagem significativa com as Tecnologias de Informação e Comunicação. Dentre os efeitos mais positivos da revolução causada pelas Tecnologias de Informação e Comunicação destaca-se a disseminação da prática de ensino/aprendizagem além das fronteiras físicas da sala de aula, e entre as diversas possibilidades, $o$ e-learning:

Entendemos o e-learning basicamente como um sistema de formação à distância que aproveita as atuais infraestruturas de internet e intranet para compartilhar ações formativas, sem que as partes envolvidas coincidam no espaço e/ou tempo e se caracteriza por modificar substancialmente a docência tradicional já que desaparece a limitação espacial e temporal. É, portanto, uma ferramenta didática. (PINO, 2008).

O vídeo é uma das mídias admissíveis para um programa de e-learning, pois incorpora duas características positivas importantes: a granularidade - o conteúdo deve ser segmentado para facilitar a assimilação de novo conhecimento e permitir uma agenda de estudos flexível; e a interatividade - exige frequente interação do estudante para manter a atenção e promover a aprendizagem (FAO, 2011).

No caso particular do Curso de Música e Tecnologia a escolha pelo vídeo (entre as possibilidades multimídia disponíveis) se baseia em várias questões: o uso frequente dos vídeos do YouTube como referência por nossos estudantes em diversas disciplinas; o fato de que o vídeo pode representar um poderoso impacto emocional e cognitivo para nossos estudantes (BERK, 2009); a popularização e difusão de dispositivos capazes de acessar plataformas/reproduzir formatos de vídeo em qualquer lugar e a qualquer hora.

A preferência pela linguagem audiovisual baseia-se em sua capacidade para atingir o espectador de forma multisensorial:

Os meios de comunicação, principalmente os áudio-vídeo-gráficos desenvolvem formas sofisticadas de comunicação sensorial multidimensional, de superposição de linguagens e mensagens, que facilitam a aprendizagem e condicionam outras formas e espaços de comunicação. (MORAN, 1995).

Cabe destacar a relevância de desenvolver processos de comunicação com maior riqueza e intensidade, buscando criar uma experiência atrativa para o estudante e aproveitando o paradigma tecnológico para explorar a já citada multisensorialidade (MORAN, 1995). O audiovisual pode ser então "compreendido como um diferencial no processamento de informações. Somente com uma adequada concepção do vídeo [...] poder-se-á aproveitar todo seu potencial educativo" (CINELLI, 2009).

É neste aspecto de "adequada concepção de vídeo" a que se refere Cinelli que se tornam relevantes os princípios da Aprendizagem Significativa de Ausubel (1968) e da 
Carga Cognitiva de Sweller (1994) que conduzem a desenvolvimento de trabalhos posteriores como os já citados Clark \& Mayer(2011) e Koumi (2006).

A Teoria da Carga Cognitiva de Sweller é uma teoria que ilustra formas de reduzir formas improdutivas de carga cognitiva e ao mesmo tempo maximizar fontes produtivas desta mesma carga, conduzindo a ambientes de aprendizagem eficientes (CLARK, NGUYEN e SWELLER, 2006). Desta forma o autor analisa o mecanismo de processamento de informações de cada indivíduo como no caso da aprendizagem significativa de Ausubel e propõe formas de tornar o novo conteúdo mais facilmente assimilável pelo estudante.

A partir da Teoria da Carga Cognitiva e de uma longa trajetória de experiências práticas foi desenvolvida a proposta de Clark e Mayer, destinada ao que eles chamam de e-learning. Por mais de vinte anos estes autores, juntos, individualmente ou associados a outros colaboradores têm proposto várias séries de princípios de instructional design para multimedia learning. Em sua publicação de 2011 e-Learning and the Science of Instruction eles propõem sete princípios que podem melhorar o potencial de aprendizagem de materiais multimídia:

\section{Princípio Multimídia}

•use texto e gráficos em vez de apenas texto

\section{Princípio de Contiguidade}

- alinhe o texto aos gráficos correspondentes

\section{Princípio de Modalidade}

- apresente o texto como áudio/narração em vez de como texto na tela

\section{Princípio da Redundância}

• explique os elementos visuais com texto na tela ou com áudio, não ambos.

\section{Princípio da Coerência}

- adicionar material pode prejudicar a aprendizagem;

\section{Princípio da Personalização}

•use um "tom" normal de conversa como um "professor virtual"

\section{Princípio da Segmentação e Treinamento Prévio}

- administrar a complexidade do assunto dividindo uma lição em partes

Num estudo financiado pelo governo finlandês no início dos anos 2000 foram abordadas as possíveis vantagens de utilização do vídeo como mediador de informações e experiências no âmbito educacional. A partir desse estudo foram estabelecidas seis características que caracterizam a Aprendizagem Significativa a partir de vídeos disponibilizados online (KARPPINEN, 2005): a) a aprendizagem é ativa; b) acontece de forma construtiva e individual; c) define atitudes colaborativas e potencializa a comunicação entre pares; d) é aplicável dentro de um contexto; e) pode acontecer de forma guiada; f) tende a ser emocionalmente envolvente e motivadora.

Uma abordagem semelhante em vários aspectos mas com considerações práticas a respeito de quando é realmente necessário utilizar um recurso como o vídeo, relativamente complexo em termos de produção e com custos mais elevados que outras formas de apresentação multimídia é apresentada por Koumi (2006). Em seu Designing Video and Multimedia for Open and Flexible Learning (2006) ele enumera técnicas e funções que exploram os pontos positivos do vídeo adicionando valor pedagógico à produção: a) vídeos que adicionam valor cognitivo ou habilidades valiosas; b) vídeos que 
adicionem o valor de uma experiência e c) vídeos que adicionem valor em termos de consolidação da aprendizagem.

Nesse sentido, o presente trabalho apresenta o relato da experiência da produção de uma vídeo aula abordando a temática "Compressão" embasada nos princípios do design instrucional que visa o gerenciamento da carga cognitiva.

\section{Encaminhamentos metodológicos}

O presente trabalho consiste num estudo descritivo qualitativo de cunho crítico-reflexivo acerca de um relato de experiência a partir de uma prática já existente na DCG de Áudio Digital Multipista I, II, II e IV, revista, analisada e comparada com o modelo de Clark e Mayer de Instrucional Design. De acordo, com Gil (2008), o relato de experiência da margem para o pesquisador relatar suas experiências e vivências associando-as com o saber científico.

Os dados utilizados neste relato de experiência foram coletados ao longo do estudo em diversas formas: anotações num tablet, gravações de áudio em telefone celular e gravador digital de voz; fotos e vídeos capturadas em telefone, tablet ou câmera fotográfica digital. A preferência por cada um dos dispositivos em diferente situações foi definida a partir de critérios como praticidade e agilidade.

Como o ponto mais importante foi sempre o registro tão imediato quanto possível das impressões, ideias ou experiências, consideramos que a qualidade de áudio ou vídeo não era relevante neste estágio e que o recurso disponível de forma mais imediata seria o preferido para não interromper o fluxo de trabalho. Se a proposta tivesse incluído a publicação posterior desta forma de diário de campo, como um vídeo blog no YouTube, por exemplo, teria sido relevante priorizar a qualidade do áudio (MINAL, 2017)

\section{Resultados e Discussão}

\section{Pré-produção}

Numa produção audiovisual típica esta etapa envolve o planejamento e a preparação do material que será utilizado ao longo do que se costuma referir como produção propriamente dita. Neste planejamento estão envolvidas decisões sobre aspectos visuais, estilísticos, técnicos e todos os que se relacionam diretamente ao conteúdo.

A partir do momento em que estabelecemos que a adesão aos Princípios de Clark e Mayer seria uma de nossas prioridades, ficou claro que precisaríamos priorizar a etapa de planejamento, como eles mesmos sugerem (MAYER, 2011). Embora alguns dos Princípios podem até ser respeitados numa produção sem extenso planejamento prévio o de Coerência, por exemplo, ao manter os elementos visuais e sonoros utilizados dentro do estritamente essencial - outros dependem de decisões que só vemos acontecendo após planejamento cuidadoso. Imaginamos, no entanto, que na medida em que um maior número de vídeos seja produzido seguindo os Princípios de Clark e Mayer, a adesão a eles possa se tornar mais natural e requerer menos tempo de planejamento e pré-produção.

Uma outra ponto relevante é que os estudantes do Curso de Música e Tecnologia manifestaram (através do survey submetido) a importância não apenas do conteúdo dos vídeos mas também da organização com que ele é apresentado. Este dado nos direciona então para um tipo de produção cujo resultado sejam vídeos cada vez mais claros, sistemáticos, sucintos e coerentes.

O formato do vídeo 
Optamos por um vídeo no estilo das vídeo-aulas tradicionais, procurando expor e demonstrar os princípios que consideramos fundamentais. Definimos que o vídeo teria uma duração entre 4 e 8 minutos se possível, por entender que esta duração está de acordo com os princípios de Clark e Mayer e por ter experiência com vídeo-aulas comercializadas com esta duração (LYNDA.COM, 2017).

Em termos de definições técnicas, decidimos por trabalhar com alguns segmentos de vídeo com apresentação e imagens de performance instrumental, combinada com captura de tela do software musical e gráficos estáticos criados em editor de imagens. Decidimos também por adicionar narração e auxílios visuais na tela do computador durante o processo de pós-produção para evitar redundância e excesso de elementos audiovisuais - desta forma as escolhas relativas a esses recursos poderiam ser consideradas numa etapa independente.

\section{O exemplo musical a ser utilizado no exercício.}

Um ponto que consideramos chave neste projeto de aprimoramento da concepção das vídeo-aulas que produzimos é a possibilidade de expansão do acervo de acordo com as necessidades dos estudantes. Sendo assim, imaginamos que um exemplo musical seria tanto mais adequado quanto maiores fossem as possibilidades de manipulação do material sonoro dentro de uma perspectiva de mixagem real.

Se alcançado este objetivo, cada um dos arquivos de áudio incluídos no exemplo (e disponibilizados para os estudantes) poderia ser foco de diversas técnicas de processamento - e que cada uma destas técnicas poderia ser tema de um novo vídeo. Preservaríamos assim o princípio de segmentação do conteúdo, como sugerido pelo $7^{\circ}$ Princípio de Clark e Mayer e permitiríamos que os estudantes estudassem e experimentassem cada uma das técnicas dentro de um contexto musical real.

O exemplo musical foi produzido a partir dessas considerações e conta com:

- uma base rítmica em forma de uma bateria programada no software de gravação e mixagem e que pode ou não ser utilizada, dependendo do objetivo do vídeo e das preferências do estudante;

- uma linha de acompanhamento de baixo elétrico programada no mesmo software, inicialmente apenas para complemento, no caso de uso da pista de bateria;

- duas pistas de violão (com cordas de aço) em forma de acompanhamento e com sonoridades ligeiramente diferentes entre si. Concebidos para serem uma das instâncias mais importantes para técnicas de processamento, e gravados acusticamente no software já citado;

- uma pista de guitarra elétrica concebida como principal elemento rítmico/melódico do exemplo musical, e que pode servir para estudo e prática de diversas técnicas de processamento;

- uma pista de acompanhamento de sintetizador programada no software e pensada para complementar os instrumentos existentes sem que seu papel seja prioritário.

\section{O conteúdo abordado no vídeo.}

Como sugere Prensky (2007), é importante oferecer ao aluno uma ampla gama de materiais didáticos/instrucionais e permitir que ele escolha seu roteiro entre aqueles que achar significativos para sua realidade e suas necessidades. Sendo assim, o intuito inicial foi o de criar um conjunto de vídeos abordando técnicas e procedimentos comuns aos alunos e profissionais da área, divididos por tópicos e tentando tanto quanto possível objetivar a granularidade apontada por Prensky (2007). Esta característica é importante, para o mesmo autor, por permitir que o estudante/aluno tenha livre acesso às partes da informação que lhe são relevantes naquele momento; fica a cargo de cada indivíduo 
estabelecer seu "roteiro" entre o material disponível e decidir a ordem (se houver uma) entre os vários tópicos abordados.

A partir destas considerações e devido a relevância do conteúdo para nossos estudantes decidimos começar pelo tópico de Processamento de Dinâmica: Compressão. Este tipo de técnica de processamento está presente, de alguma forma, em qualquer produção musical publicada. Ela se refere, de forma geral, às técnicas envolvidas na manipulação e controle da amplitude ou intensidade dos elementos sonoros de uma gravação (COREY, 2010).

\section{Produção}

Esta é uma das etapas mais complexas em termos técnicos e também, na concretização de tudo que foi definido como prioritário em termos de Instructional design. É nessa etapa onde o material propriamente dito vai ser gerado, em suas diversas formas: gravações de áudio de instrumentos, voz/narração, vídeo dos instrumentos, captura de tela no software de gravação/mixagem e produção dos gráficos estáticos.

Cada uma destas etapas tem suas próprias dificuldades, principalmente aquelas com gravação de áudio e/ou vídeo, onde muitas vezes são necessários vários takes (ou tomadas - cada uma delas sendo uma versão gravada). Para evitar gerar material desnecessário e redundância, assim como para manter o tempo de gravação tão controlado quanto possível, o recurso mais comum é a produção de um roteiro. Este roteiro lista cada elemento a ser produzido e sua ordem dentro do produto final. A produção de um roteiro claro e detalhado foi uma de nossas prioridades antes de realizar qualquer gravação.

O roteiro do vídeo.

- Abertura: título sobre fundo claro, fonte simples e bem visível - fade (transição) para imagem do software de gravação e mixagem (Steinberg Cubase). Movimento panorâmico mostrando medidores de nível e plug-ins de compressão abertos na tela. Como música de fundo, início do tema instrumental produzido (entre 15 e 20 s); fade para fundo branco.

- Saudação do professor/apresentador: imagem inicial de ambiente de trabalho (computador, monitores de estúdio). Tom informal e amistoso para apresentar a série de vídeos sobre compressão e especificar que este primeiro trata dos seus Aspectos Básicos. A imagem muda para a tela do Cubase enquanto aparecem os compressores de cada uma das pistas instrumentais que serão abordadas no vídeo (25 a $35 \mathrm{~s}$ ); fade para fundo branco.

- Fade rápido para tela do Cubase com compressores abertos. São apresentados conceito, principais usos; a seguir, menciona o modelo de compressor/software escolhido para a demonstração e apresenta os parâmetros básicos de compressão. Sem trilha sonora de fundo. ( 30 e $40 \mathrm{~s}$ ); fade para fundo branco.

- Apresentação dos parâmetros básicos de compressão, em forma de narração: os parâmetros de Threshold, Ratio, Attack e Release são apresentados enquanto a captura de tela mostra a localização de cada função no compressor. Acompanhando cada início de descrição em áudio o nome do parâmetro aparece escrito na tela para reforçar sua assimilação: (threshold: 25 a $30 \mathrm{~s} ;$ ratio: 25 a 30 s; attack: 30 a 40 s; release: 25 a 30 s); fade para fundo branco.

- Apresentação do conceito e Gain Reduction (ou redução de ganho, definindo quanto da amplitude total foi atenuado pelo compressor). A expressão aparece escrita na tela. Imagem do parâmetro no compressor. Imagem da pista de áudio antes e depois de aplicada a compressão para demonstrar a diminuição da gama dinâmica (35 a 40 s); fade para fundo branco. 
- Demonstração de que cada pista de áudio: dependendo do conteúdo e da sonoridade pretendida pode ser processada de formas diferentes. Mostrar a pista utilizada na demonstração dos parâmetros básicos (sugestão: guitarra elétrica) e uma segunda possibilidade de ajustes para obter sonoridade diferente. Mostrar compressão numa segunda pista de áudio (sugestão: primeiro violão de acompanhamento) e mostrar uma segunda alternativa de sonoridade baseada em diferentes parâmetros (50 a $55 \mathrm{~s}$ ); fade para fundo branco.

- Explicação sobre a subjetividade e o caráter pessoal na sonoridade que cada pessoa procura quando faz processamento de áudio e mixagem: despedida informal, convidando os estudantes a acessarem os demais vídeos sobre compressão. Se os vídeos fossem pensados para publicação num canal da plataforma YouTube, nesta parte convidaríamos o público a inscrever-se no canal e acompanhar as postagens posteriores ( $25 \mathrm{a} 30 \mathrm{~s}$ ). Nesta sequência final podemos ter a trilha sonora do exemplo musical tocando ao fundo se não parecer distrair o espectador; fade para fundo branco.

- Apresentação de créditos muito simplificados, uma ou duas telas. Tela final com copyright. No fundo a trilha pode continuar desde o segmento anterior.

\section{A produção e gravação do exemplo musical.}

Os pontos básicos do conceito para o exemplo musical foram estabelecidos durante o processo de planejamento, levando em consideração aspectos estéticos, técnicos e de usabilidade futura. O estilo musical escolhido para o exemplo foi o de folk/rock instrumental por causa dos recursos disponíveis em nosso home studio e visando tornar cada uma das pistas de áudio tão adequada quanto possível para entendimento dos fundamentos de compressão.

Os passos da produção e gravação do exemplo foram os seguintes:

- - Utilizando violão com cordas de aço, esquematizamos uma sequência harmônica e rítmica que nos pareceu interessante para o desenvolvimento da peça musical como um todo. Quando o esboço inicial pareceu adequado, fizemos uma gravação de vídeo com um tablet.

- Preparamos por escrito a estrutura básica da peça de acordo com o esboço inicial, delimitando as partes para criar variedade e um sentido de continuidade. Desta forma deixamos espaço para, no futuro, desenvolver mais a peça pela inclusão de novos instrumentos ou partes. Estas novas partes ou elementos musicais podem ser positivos no sentido de exemplificar e desenvolver outras técnicas de processamento de áudio no futuro.

- Programamos, dentro do software Maschine, a linha de acompanhamento rítmico na bateria, como definido na etapa de planejamento. Após estruturar a bateria seguimos com a programação do baixo elétrico, para completar o grupo instrumental que normalmente estabelece a base de uma composição de folk/rock. A preferência pelo Maschine como ferramenta para esta parte do trabalho se deve à praticidade de programação, ao integrar um conjunto de hardware e software, simplificando e agilizando o trabalho.

- Adicionamos uma linha de acompanhamento de sintetizador ainda no mesmo Maschine, procurando gerar uma peça com suficientes elementos para dar aos estudantes uma experiência envolvente. Optamos por um timbre que se integrasse de maneira adequada com os violões de aço, procurando que se complementassem.

- Finalizamos o trabalho no software Maschine exportando as faixas de áudio individuais para bateria, baixo elétrico e sintetizador. 
- Importamos as faixas de áudio já produzidas para um novo projeto no software de gravação e mixagem Cubase.

- Realizamos a gravação das duas faixas de violão de aço com um conjunto de microfone e interface de áudio num computador pessoal tipo desktop. A gravação de cada uma das faixas de violão foi realizada ouvindo a trilha já produzida (bateria, baixo e teclado) através de fones de ouvido.

- Ouvindo a trilha produzida já com os violões, experimentamos improvisando na guitarra elétrica até chegar a um esboço inicial de linha rítmico/melódica. A guitarra foi tocada através de um conjunto de amplificador e caixa acústica apropriada.

- Realizamos a gravação, utilizando um microfone em frente da caixa acústica mencionada, de 4 versões da linha que estruturamos para a guitarra elétrica. Esta técnica de registrar várias versões de um mesmo material é comum em produção musical e permite fazer escolhas posteriores, inclusive combinando partes de versões diferentes.

- A partir de todas as faixas de áudio programadas e gravadas preparamos uma mixagem inicial, equilibrando o volume de cada um dos elementos dentro do que em nossa subjetividade pareceu adequado.

- Decidimos por preparar duas versões diferentes desta mixagem da peça: uma básica, sem compressão nos violões nem guitarra, para utilizar na parte do vídeo onde explicamos a técnica; outra com compressão e adição de efeitos, para uso na abertura e no encerramento do vídeo. Nesta segunda versão tivemos a intenção de chegar o mais próximo possível de exemplos musicais lançados comercialmente, que costumamos utilizar como referências com nossos estudantes no Curso.

A gravação do vídeo de apresentação.

Nesta parte da produção tínhamos dúvidas quanto à quantidade de elementos que deveríamos acrescentar, procurando mostrar ao espectador um lugar e equipamento que apoiem uma imagem de ambiente profissional (CHAPMAN, 2015). Embora esta ideia possa ser compreendida como conflitante com o Princípio de Coerência, procuramos um ponto intermediário.

A gravação foi realizada captando simultaneamente vídeo e áudio, sincronizado posteriormente a partir de um sinal sonoro (idem). Uma câmera de vídeo do tipo mirrorless posicionada num tripé gravou o vídeo, enquanto um microfone - visível em cena - conectado a uma interface de áudio e ao computador serviu para gravar a voz no software Cubase.

Procurando agilizar a produção aproveitamos esse mesmo equipamento já ajustado para gravar a narração das descrições de todo o vídeo, mantendo várias versões, de acordo com o previsto no roteiro do item 4.2.1. Preparando-nos para a possibilidade de gravar novas versões destes áudios para narração, tivemos o cuidado de anotar posicionamento e distância do microfone até o narrador, assim como os ajustes feitos na interface de áudio. Estes pequenos cuidados permitem manter a uniformidade do material e evitam desperdício de tempo e esforço, evitando que fosse necessário regravar o material na íntegra.

A gravação do vídeo de captura de tela no computador.

Este é um estágio crítico no processo de produção, por ser onde geramos a maior parte do vídeo utilizado, e foi executado no software Screenium 3. Este software foi o escolhido, apesar de novo para nós, por ter um adequado conjunto de recursos, ser estável e de custo acessível. 
Realizamos a captura de tela de todo o processo de ajustes de cada um dos compressores em suas pistas de áudio respectivas, incluindo uma segunda possibilidade para cada um deles. Este segunda possibilidade era necessária por causa do que tínhamos previsto no roteiro, em que decidimos mostrar duas das múltiplas possibilidades de ajustes de compressores de acordo com a sonoridade pretendida. Para evitar a possibilidade de que algum travamento de software nos levasse a perder partes significativas do trabalho gravado, decidimos fragmentar as capturas de vídeo separando a compressão de cada pista de áudio. Este cuidado foi tomado por termos tido experiência de travamento e consequente perda com softwares anteriores de captura de tela. Em cada segmento de vídeo gravado capturando a tela o software Screenium realizou também a captura do áudio proveniente do software Cubase. Todos os arquivos de vídeo da captura foram reunidos, organizados e listados para uso na pós-produção/montagem final.

\section{Pós-produção.}

Esta é uma etapa de grande complexidade em termos técnicos criativos e também na concretização de tudo que foi definido como prioritário em termos de instructional design. Uma parte longa e importante no trabalho foi realizado em software de captura de tela (Screenium 3), mas poderia ser realizado em outros softwares de edição de vídeo digital (conhecidos no meio como NLEs). A opção por um software se baseou em simplicidade de uso em relação às possibilidades e recursos oferecidos, assim como no custo relativamente baixo comparado a outras alternativas. Dentro deste software foram incorporados todos os arquivos de vídeo e gráficos assim como os arquivos de áudio da narração.

Todos arquivos de vídeo e áudio foram importados no software Screenium, sendo o áudio da narração editado para evitar pausas desnecessárias e manter sua duração tão curta quanto possível, sem depreciar a inteligibilidade do texto. Esta narração - editada de acordo com as durações do roteiro - serviu de base para definição dos demais elementos audiovisuais.

As versões de captura de tela da versão finalizada do exemplo musical foram inseridos no início do vídeo e no final, a partir das despedida, sendo que os segmentos de captura de tela foram editados (cortados e ajustados) para acompanhar o fluxo ditado pela narração do texto contendo as explicações e descrições. Em seguida foram adicionados gráficos estáticos (capturas estáticas da tela do computador, posteriormente editadas) para reforçar as diferenças existentes entre os gráficos das pistas individuais antes e depois da compressão. A seguir foram adicionadas marcações, efeitos de zoom (magnificação da imagem) e destaques visuais nos segmentos de captura de tela.

Os elementos textuais na tela para reforçar pontos-chave do texto da narração foram adicionados com o cuidado de manter a sincronização ( $1^{\circ}$ Princípio) e de não criar problemas de redundância ( $4^{\circ}$ Princípio). Foram adicionados ainda os título inicial e os créditos finais. Logo em seguida, o vídeo foi exportado do software Screenium para um formato de mp4 para facilitar sua exibição.

Um dos vídeos produzidos de acordo com os princípios de Mayer do Instrucional Design está disponível no endereço <https://www.youtube.com/watch?v=QzrvZI0R5zA $>$.

\section{Considerações Finais}

Um dos principais resultados deste processo de pesquisa aplicada na produção de uma vídeo-aula foi a percepção da complexidade da proposta inicial. Muitas vezes observamos vídeos produzidos por terceiros em que, quando comparados com o modelo de Clark e Mayer, é possível perceber quanto poderia ter sido melhorado ou otimizado durante seu 
processo de produção. Esta capacidade de estabelecer um "olhar externo" de avaliação em cada etapa provou-se um grande desafio no processo prático da produção: as falhas, deficiências ou detalhes foram muito mais difíceis de perceber e solucionar que em nossos vídeos antigos, "pré-Clark e Mayer".

Constatamos na prática a viabilidade de integrar os Princípios de Clark e Mayer no processo de produção; e consideramos especialmente significativo que, à medida em que o trabalho se desenvolvia, se tornava cada vez mais natural seguir esses Princípios. Em termos desta assimilação dos Princípios de Instructional Design, imaginamos uma analogia com a gramática na linguagem falada: é uma estruturação sistematizada que incorporamos à nossa vivência, e que utilizamos de forma natural e cotidiana.

\section{Referências}

BERK, R. A. Multimedia teaching with video clips: TV, movies, YouTube, and mtvU in the college classroom. International Journal of Technology in Teaching and Learning. [S.l.]: 2009.

AUSUBEL, David P. Aquisição e retenção de conhecimentos: Uma perspectiva cognitiva. Lisboa, Paralelo, 2000.

CINELLI, Nair P. F. A influência no vídeo no processo de aprendizagem. Florianópolis, UFSC, 2009.

CLARK, R. C.; MAYER, R. E. e-learning and the Science of Instruction: proven guidelines for consumers and designers of multimedia leraning. Pfeiffer, San Francisco, 2011.

CLARK, R. C.; NGUYEN, F.; SWELLER, J. Efficiency in Learning: Evidence-Based Guiodelines to Manage Cognitive Load. Pfeiffer, San Francisco, 2006.

COREY, J. Audio Production and Critical Listening: Technical Ear Training. Elsevier, Oxford, 2010 .

FAO: FOOD AND AGRICULTURE ORGANIZATION OF THE UNITED NATIONS. ELearning Methodologies: A Guide for Designing and Developing E-Learning Courses. Rome, 2011.

KARPPINEN, P. Meaningful learning with digital and online videos: Theoretical perspectives. AACE Journal, 2005.

KOUMI, J. Designing Video and Multimedia for Open and Flexible Learning. Routledge, Oxon, 2006.

MORAN, J. M. O Vídeo na Sala de Aula. Comunicação \& Educação. São Paulo: ECA-Ed. Moderna, jan./abr. 1995.

PINO, M. Aplicaciones de herramientas de e-learning a la docencia presencial. Revista de Formación e Innovación Educativa Universitaria. [S.1.]: 2008.

PRENSKY, M. Changing Paradigms - from "being taught" to "learning on your own with guidance”. [S.1.]: Educational Technology, July-Aug, 2007.

TOULSON, R. Creation of Media-Based Learning Material for Audio and Music

Technology. Networks, n. 4, 2011.

SWELLER, J. Cognitive Load Theory, Learning Difficulty, and Instructional Design. Learning and Instruction, Vol. 4, 1994. 